\title{
The Epistemic Engine: Sequence Organization and Territories of Knowledge
}

\author{
John Heritage \\ Department of Sociology \\ University of California at Los Angeles
}

\begin{abstract}
This article reviews a range of conversation analytic findings concerning the role of information imbalances in the organization of conversational sequences. Considering sequences launched from knowing and unknowing epistemic stances, it considers the role of relative epistemic stance and status as warrants for the production of talk and as forces in the process of sequence production and decay.
\end{abstract}

It is now more than 30 years since Charles Goodwin, in a classic article, analyzed the following utterance: "I gave, I gave up smoking cigarettes::. (0.4) I-uh: one-one week ago t'da:y acshilly." The article observed that the utterance was initially designed for, and addressed to, an unknowing $(\mathrm{K}-)$ recipient (Don, a dinner guest at the table). Finding little supportive uptake from the latter, the speaker shifts his gaze to his wife (Beth) and adds a small increment ("one-one week ago t'da:y acshilly,") suggesting that today is a minilandmark or anniversary in his passage to exsmoker status. This increment, Goodwin argues, is appropriately constructed for Beth because, while she is aware that he has quit smoking, she may not be cognizant of the day or date on which he quit. As Goodwin notes, "with the addition of this section to the sentence, the news that John has stopped smoking cigarettes is transformed into a different piece of news: that today is an anniversary of that event. Such an anniversary is a new event that none of the parties present, including Beth, need be expected to know about" (Goodwin, 1979, p. 100).

As Goodwin's (1979) analysis makes clear, the driving force, indeed the ultimate warrant, both of the initial utterance and of its subsequent modification, is epistemic: the conveying of news to otherwise unknowing recipient(s). Crediting it to Sacks, Goodwin describes the normative principle that underpins the sequence as the "general rule that provides that one should not tell one's coparticipants what one takes it they already know" (p. 100). Three years previously, Terasaki $(1976 / 2004)$ had pursued this same theme in a remarkable analysis of pre-sequences designed to discriminate knowing from unknowing recipients as a preface to announcements. And a few years subsequently, Heritage (1984) documented the extent to which participants index a claimed

I would like to thank Steve Clayman, Paul Drew, Nick Enfield, Kobin Kendrick, Steve Levinson, and Sandy Thompson for their comments and reactions to an earlier draft of this article.

Correspondence should be sent to John Heritage, UCLA Department of Sociology, 264 Haines Hall, 375 Portola Plaza, Los Angeles, CA 90095. E-mail: heritage@ucla.edu 
"change of state" (from $\mathrm{K}-$ to $\mathrm{K}+$ ) after receiving answers to their questions. The first two studies vividly displayed that speakers are exquisitely sensitive to their epistemic positions relative to addressees, as a condition of developing a turn at talk (Goodwin, 1979) or initiating a sequence (Terasaki, 2004), while the third showed that this sensitivity is also indexed by recipients in the aftermath of interactional sequences by registering that information has been conveyed.

The idea that "information" is a key element in communication, motivating and warranting contributions to talk, is hardly a new one. It is a staple of communication theories from Shannon and Weaver (1949) onward, of a wide variety of functional linguistic theories focusing on the given-new distinction (Chafe, 1994; Clark \& Haviland, 1977; Halliday \& Hasan, 1976; Prince, 1981), and many, comparatively diverse, pragmatic theories (Grice, 1975; Levinson, 2000; Sperber \& Wilson, 1986) dealing with sentence construction and interpretation. During this same period, semantic theorists (e.g., Kamp, 1981; Stalnaker, 1978) began to develop dynamic models of information flow. As Levinson (in press) summarizes it:

\begin{abstract}
Most of these models assumed a pool of shared information or "common ground" and asked how specific linguistic structures encoded instructions about how to update this common ground (see van Eijck, J. \& Visser, A., 2010). Meaning then can be equated with contextual change. An assertion, for example, might encode presuppositions that should already be in the common ground, while having new asserted content that should be added to it. Questions partition information states and their answers eliminate some of these partitions (Groenendijk 1998), so updating common ground.
\end{abstract}

In general, however, conversation analysis (CA) stood aside from these trends, despite clear evidence that acknowledging new information as new and thereby enacting the updating of common ground is the first order of business transacted by many "sequence closing thirds" (Schegloff, 2007) and related acknowledgments. Consider the following announcement sequence:

\title{
(1) [Terasaki 2004]
}

$\begin{array}{rlll}1 & \text { Ron: } & \text { I fergot t'tell y'the two best things that } \\ 2 & & & \text { happen'tuh me t'day. } \\ 3 & \text { Bea: } & \text { Oh super.=What were they } \\ 4 & \text { Ron: } & \text { I gotta B plus on my math test, } \\ 5 & \text { Bea: } & \text { On yer final? } \\ 6 & \text { Ron: } & \text { Un huh? } \\ 7 & \text { Bea: } & \text {-> } & \text { Oh that's wonderful } \\ 8 & \text { Ron: } & \text { And I got athletic award. } \\ 9 & \text { Bea: } & \text { REALLY? } \\ 10 & \text { Ron: } & \text { Uh huh. From Sports Club. } \\ 11 & \text { Bea: } & -> & \text { Oh that's terrific Ronald. }\end{array}$

Here, at lines 7 and 11, the very first element of Bea's turn acknowledging Ron's news is to register it as "news" with the "change of state" token "oh." Only subsequently does Bea go on to register its valence (as good or bad [Maynard, 2003]) with affiliative assessments. These two responses address what Schegloff has termed the "double-barreled" nature of many conversational actions (Schegloff, 2007). The ordering of the two-register something as news before 
doing anything else with it - appears to be universal or close to universal in English, and perhaps in other languages as well (Hayano, 2011). ${ }^{1}$ These elemental conversational phenomena have not been much remarked on in the literature of conversation analysis. Rather they have tended to be subsumed under the topic of "recipient design" or lumped into an amorphous category of "sequence-closing thirds."

This article considers the role of territories of knowledge in the motivation of interactional sequences. It argues that when a speaker indicates that there is an imbalance of information between speaker and hearer, this indication is sufficient to motivate and warrant a sequence of interaction that will be closed when the imbalance is acknowledged as equalized for all practical purposes. In Sequence Organization, Schegloff (2007) writes that there are principles of sequence organization other than those centered on the notion of adjacency pairs per se, mentioning storytelling and other kinds of "telling" sequences (pp. 41-44). However at the same time, he also notes the significant difficulties and complications in tracing through postexpansions to adjacency pairs in sequential or topic terms. This article is conceived as a contribution to understanding these alternative principles of sequence organization, with the suggestion that information imbalance is one of these principles.

The argument is prosecuted through two lines of inquiry: analysis of sequences arising from first speaker initiations from unknowing $(\mathrm{K}-)$ positions, and those arising from first speakers in knowing $(\mathrm{K}+)$ positions. In each case, the discussion moves from overt "on record" instantiations of these positions as warrants for talk, that could be alternatively characterized as adjacency-pair firsts, such as questions or announcements (Schegloff, 2007; Stivers \& Rossano, 2010) toward less overt and more subtle and indirect expressions of them that could not easily be so characterized. Whether overt and "on the record" or covert and "off the record," I argue that these expressions of epistemic imbalance drive sequences. I begin with a brief overview of territories of knowledge.

\section{TERRITORIES OF KNOWLEDGE: EPISTEMIC STATUS AND EPISTEMIC STANCE}

The notion of territories of knowledge (or epistemic domains [Stivers \& Rossano, 2010]) was first canvassed by Labov and Fanshel (1977) in their distinction between A-events (known to $\mathrm{A}$, but not to $\mathrm{B}$ ) and B-events (known to B, but not to A), using this to ground an analysis of declarative questions in which B-event statements made by A (e.g., "You're going to the movies.") would count as requests for information. It was enlarged by Kamio (1997), who systematized the idea that both A and B each have their own territories of information, and that any specific element of knowledge can fall into both of them, but often to different degrees. Drawing these ideas together, we can consider relative epistemic access to a domain as stratified between actors such that they occupy different positions on an epistemic gradient (more knowledgeable $[\mathrm{K}+]$ or less knowledgeable $[\mathrm{K}-]$ ), which itself may vary in slope from shallow to deep (Heritage, 2010, in press; Heritage \& Raymond, in press). We will refer to this relative positioning as epistemic status, in which persons recognize one another to be more or less knowledgeable concerning some domain of knowledge as a more or less settled matter of fact (see Heritage, 2012/this issue). The epistemic status of each

\footnotetext{
${ }^{1}$ See also Schegloff's discussion of "composite" postexpansions (Schegloff, 2007, pp. 127-142).
} 
person, relative to others, will of course tend to vary from domain to domain, as well as over time, and can be altered from moment to moment as a result of specific interactional contributions.

Epistemic status is to be distinguished from epistemic stance. Epistemic stance concerns how speakers position themselves in terms of epistemic status in and through the design of turns at talk. While there is often congruence between epistemic status and epistemic stance such that the epistemic stance encoded in a turn is aligned to the epistemic status of the speaker, this congruence is not inevitable. The additional concept of epistemic stance is necessary because epistemic status can be dissembled by persons who deploy epistemic stance to appear more, or less, knowledgeable than they really are.

In considering the role of territories of knowledge in sequence organization, two main avenues present themselves. First, speakers can position themselves in a relatively unknowing (or $\mathrm{K}-$ ) position relative to others concerning the matter at hand, thereby initiating sequences by inviting or eliciting information from a projectedly more knowing (or $\mathrm{K}+$ ) recipient. Alternatively, knowing $(\mathrm{K}+)$ speakers can simply initiate talk concerning the matter at hand, thus launching a sequence, finding a warrant for this conduct by projecting their recipients to be in a relatively unknowing $(\mathrm{K}-)$ position. We will deal with each of these possibilities in turn.

\section{RECIPIENT INITIATIONS: K- INITIATIONS}

The role of information requests in the motivation of sequences of interaction is surely beyond any doubt. Information requests are a primary prototype of the first pair-part of an adjacency pair (Schegloff, 2007; Stivers \& Rossano, 2010), making second pair-parts required, noticeably absent, and contiguously responded to as a matter of normative obligation (Sacks, 1987; Schegloff, 1972) and empirical practice (Stivers et al., 2009). Information requests are actions in which resources for communicating epistemic stance (such as, commonly, interrogative syntax) are aligned with the real-world relative epistemic status of the parties (e.g., knowing $[\mathrm{K}+]$ for the recipient, and unknowing [K-] for the requester) to constitute the action (Heritage, 2012/this issue). In the following sequence, three discrete requests for information by Nancy motivate corresponding responses from her friend Hyla. In each case, the information (about Hyla's new boyfriend) is clearly in Hyla's epistemic domain, and the status of each as an information request is reinforced and placed explicitly on record by the use of interrogative syntax and rising intonation:

(2) [HG:II:25]

$\begin{array}{lll}1 & \text { Nan: } & \text {.hhh Dz he 'av 'iz own apa:rt[mint?] } \\ 2 & \text { Hyl: } & \\ 3 & \text { Nan: } & =\underline{\text { Oh }:}, \\ 4 & & (1.0) \\ 5 & \text { Nan: } & \underline{\text { How didju git 'iz Yumber, }} \\ 6 & & \text { (.) } \\ 7 & \text { Hyl: } & \text { I(h) (.) c(h)alled infermation'n San }\end{array}$




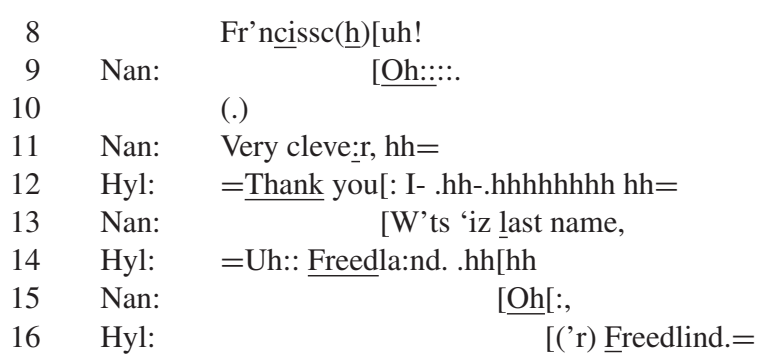

Each of these questions is, in Schegloff's (2007, p. 78) terms, "type-specifying": It specifies what a response should contain (for example a yes or no, a name, etc.). All of Hyla's responses are type conforming (Raymond, 2003) and supply information of the type requested. Subsequent to each of Hyla's responses, the response is acknowledged as having conveyed sought-after information, that is, as an "answer" to a "question," by the deployment of "oh" (at lines 3, 9, and 15)—a "sequence closing third" (Schegloff, 2007, p. 118). In this context, however, it is important to register the basis on which these sequences are closed. A request for information positions the requester as occupying an unknowing $(\mathrm{K}-)$ epistemic status and the recipient as occupying a knowing $(\mathrm{K}+)$ one. The "change of state" proposal carried by "oh" indexes an epistemic shift concerning the $\mathrm{K}-$ position previously adopted by the questioner (Heritage, 1984). This in turn indexes not only that the question was asked in search of information, but also in search of the information that is in fact provided. It does not, therefore, invite expansion. In (2) this is apparent in the gaps intervening between each question-answer sequence and the next (at lines 4 and 10), and by the fact that the talk is renewed in each case by a new question. Here then, each sequence is opened through a $\mathrm{K}$ - proposal and terminated through the provision of a response that indicates that a "gap" in information is closed and the imbalance in information has been equalized, for all practical purposes. In each sequence, the epistemic engine runs its course.

A related case is the following, in which Lesley quizzes her mother about an herbal medication that she has apparently recommended (see line 15).

\section{(3) [Field 1:1:89-94]}

$\begin{array}{llll}1 & \text { Les: } & & \text { Uh didyuh get yer garlic tablets. } \\ 2 & \text { Mum: } & \text { Yes I've got them, } \\ 3 & \text { Les: } & & \text { Have yuh t- started tak[ing th'm } \\ 4 & \text { Mum: } & & \text { [I started taking th'm t'da:y } \\ 5 & \text { Les: } & -> & \text { Oh well do:n[e } \\ 6 & \text { Mum: } & & \text { [Garlic'n parsley. } \\ 7 & \text { Les: } & \text { THAT'S RI:ght. [BY hhoh-u-Whole Food? } \\ 8 & \text { Mum: } & \\ 9 & & (0.3) \\ 10 & \text { Mum: } & \text { Whole Foo:ds ye[s, } \\ 11 & \text { Les: } & \text { [YES well done, } \\ 12 & & (0.3)\end{array}$




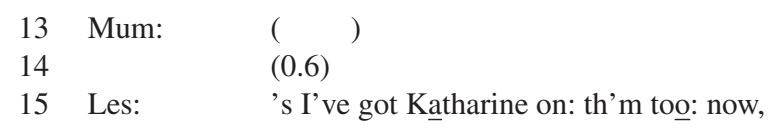

After briefly expanding this interrogation at line 3, Lesley closes the sequence at line 5 with an "oh" that registers the information and "well do:ne" that treats the information as sufficiently complete to enable this assessment. After a brief postexpansion (lines 6-10), Lesley uses a similar assessment (now without the "oh") to terminate the sequence (line 11).

Assessments on their own may also function as "sequence closing thirds" (Schegloff, 2007, p. 123). Again it may be suggested that they do so by indicating that an epistemic gap has been closed to the point that an assessment is both possible and desirable. In the first of two examples in (4), an apparently trouble-premonitory response is ignored with a bland assessment (Heritage, 1998; Jefferson, 1980), while in the second, a bland "no news" response is blandly acknowledged:

(4) [TG: 1: 27-33 (Schegloff 2007: 124)]

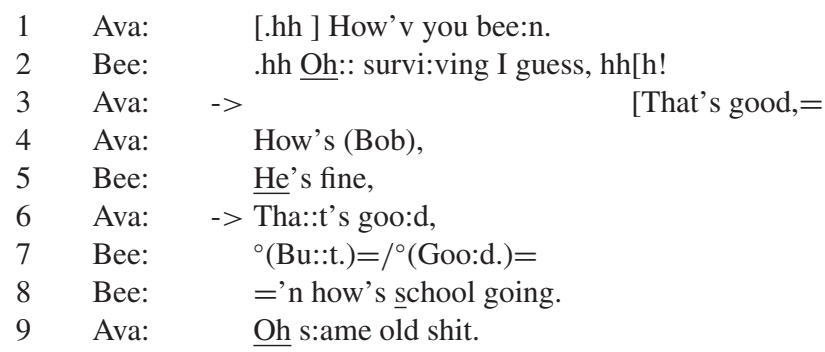

After each assessment (lines 3 and 6), new information-request-initiated sequences are begun (lines 4 and 8).

In sum, just as speakers may deploy claims of $\mathrm{K}-$ epistemic status to initiate sequences, so too they can deploy "change of state" proposals and assessments to invoke epistemic claims that close them. Across all the cases involving the use of "sequence closing thirds" to terminate these epistemically driven sequences, the interaction progresses through a process of "boundaried" or "segmented" topic organization (Button \& Casey, 1985; Jefferson, 1984).

Requests for information that invoke a $\mathrm{K}$ - epistemic position explicitly or "on the record" using interrogative morphosyntax are not the only means by which speakers can solicit information. As Pomerantz (1980) observed 30 years ago, the assertion of information that is incomplete or inadequate relative to an interlocutor (e.g., "type 2 knowables"-matters that are known by report, hearsay, or inference) can achieve the same objective. This is clearly illustrated in (5).

(5) [Rah:12:4:ST]

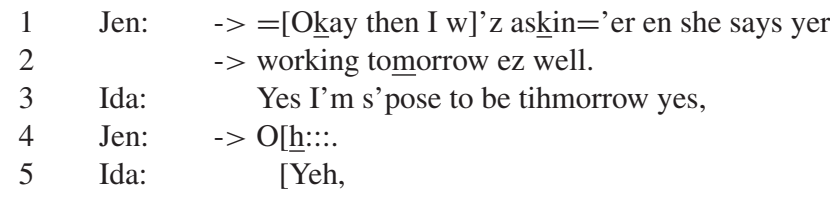


Here Jen's third-party "hearsay" report solicits confirmation from the one person in whose epistemic domain the information clearly falls. ${ }^{2}$

In (6), which concerns a company's financial affairs, Fred launches a declarative request for information from a $\mathrm{K}$ - position. The situation is complex. Skip works in accounts and has expertise about the details of the company's cash flow, but Fred is a director in the company. Fred's request for information is begun as an interrogative ("do we owe:"), which is then revised to a declarative "we haven' paid any of the (․ㅣmans) "n people like that yet," and finally overtly indexed as a $\mathrm{K}-$ supposition with "I take it."

(6) [Field U88:1:10: 26-40]

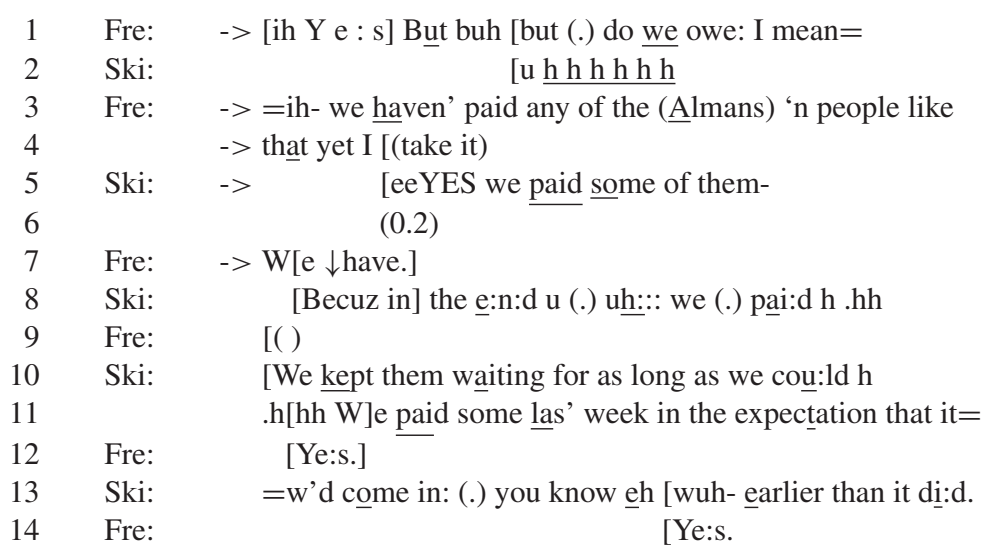

Following Skip's response that some of the company's bills have been paid (line 5), Fred specifically registers this information as counter to expectations ("We $\downarrow$ have." [line 7]). Thereafter Skip proceeds to defend the decision to pay their creditors by asserting that they had delayed as long as possible and eventually paid their some of the bills in the misplaced expectation (line 13) that they themselves would be paid on time. In addition to its other features, Fred's inquiry is clearly designed to favor the likelihood that bills have not been paid (a desirable outcome from a cash-flow point of view), and indeed the utterance was likely revised from an interrogative to a declarative form to this end. The suppositional "I take it" adds a mild epistemic downgrade to what is otherwise an assertive request for information (Heritage \& Raymond, in press). Here both of Fred's turns solicit information by declaratively formulating (lines 3-4) and retroactively reconfirming (line 7) a $\mathrm{K}$ - position.

While the previous cases involve segmented topic initiations, epistemic downgrades can also be deployed to invite sequence expansion. Very common in this context is the use of inference marked declarative utterances that address knowledge or information that is properly in the recipient's epistemic domain. The following case is offered on behalf of numerous instances

\footnotetext{
${ }^{2}$ In a parallel analysis, Goodwin (1986, p. 298) describes a wife's launch of a story that is managed by saying "Mike siz there w'z a big fight down there las'night." Here Mike's wife, Phyllis, is not the direct experiencer of the event (though evidently she has been told about it), and she uses this report to invite Mike to describe the event to the other conversational participants present who are unaware of the event or its details.
} 
of this usage. In this case, Nancy is talking about her unwilling entanglement in the financial affairs of an estranged family member. Having learning that Nancy "forwards his mail" (lines 7, 10), Emma offers the declaratively framed inference that "Yih know wher'e is the:n,"information that is absolutely within Nancy's epistemic domain and is clearly indexed as such by the postpositioned inference marker "then."

(7) [NB II:2:10(R)]

1 Nan: [So: I js took th'sekint page u th'letter? 'n (.) stuck

2 th'fifty dollars: check innit? ' $\mathrm{n}$.hhhhh (0.2) mailed it $\mathrm{t}$ '

3 Ro: 1.

$4 \quad \overline{(0.3)}$

5 Nan: $\quad$ No note no eh $\underline{I}$ haven't written a word to im.

$\begin{array}{lll}6 & & (0.3) \\ 7 & \text { Nan: } & \text { I }[j s t ~ u h, ~ h \text { for'd iz mai:l stick it in th'onvelope'n }\end{array}$

8 Emm: $\quad\left[{ }^{\circ} \mathrm{Mm}:{ }^{\circ}\right.$

$9 \quad(0.4)$

10 Nan: $\quad$ send it all on up to im en .hhh[hhh

11 Emm: -> [Yih know wher'e is the:n,

$12 \quad(0.8)$

13 Nan: I $\quad$ have never had any of it retu:rned Emma, $\mathrm{h}$

14 Emm: $\rightarrow$ Oh::.

15 Nan: At a 111, so: [I jist assoom.......

Perhaps to resist any trailing suggestion of continuing intimacy indexed in Emma's inquiry, Nancy responds with a "transformative answer" (Stivers \& Hayashi, 2010). Subsequently Emma acknowledges the response (line 14) with a change of state $(\mathrm{K}-\rightarrow \mathrm{K}+$ ) oh-receipt that acknowledges her relative lack of information (Heritage, 1984).

So far we have illustrated cases of segmented topic initiations and sequence expansions, but epistemic downgrades can also be deployed to achieve stepwise topic shifts (Jefferson, 1984; Sacks, 1992b). In the following case, Vera is describing the abrupt and unexpectedly early departure of her son (Bill) and his family from her home that day. Her friend Jenny's invitation for coffee that morning had had to be abandoned, and Vera is disappointed that her family wouldn't stay for lunch before they left, elaborating on this with a fair degree of detail (Raymond \& Heritage, 2006):

(8) [Rahman 14: 230-252]

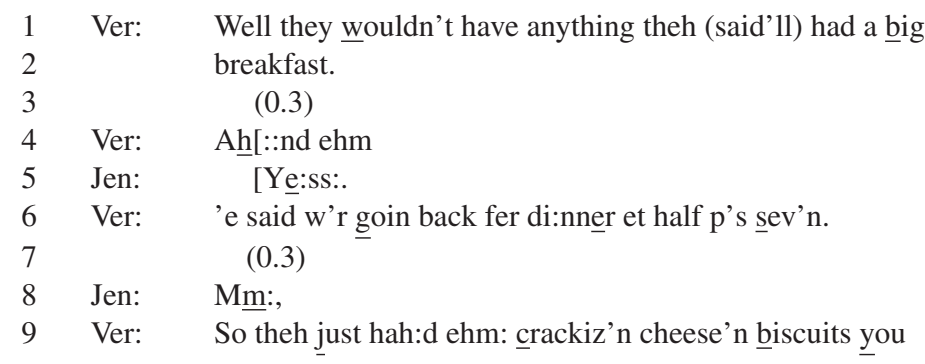


10

11

12

13

14

15

16

17

18 Ver:

19 Jen:

20 Ver:

21 Jen:

22 Ver:

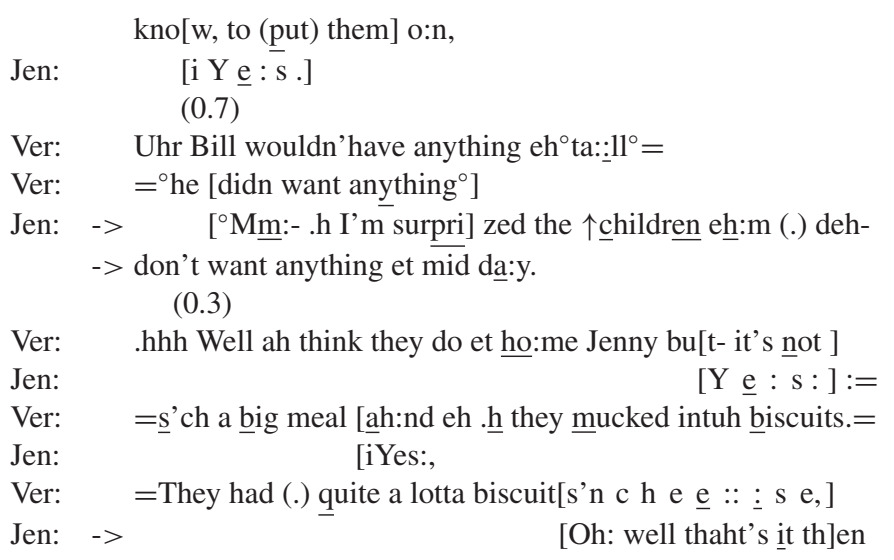

At the point where Vera's description is clearly winding down (lines 13-14), some response becomes due. Jenny responds with a turn that begins with "I'm surprised that ..." The remainder of her turn focuses on the general eating habits of the children (via the use of "don't want") rather than on what they ate on the particular morning in question (e.g., "didn't want"). In this way, Jenny launches a 'safe' inquiry, prompting an elaboration of the topic from Vera, in lieu of her own emerging obligation to evaluate its details. The expression "I'm surprised that ..." claims a lack of relevant detail that would permit her to grasp the circumstances described and, in response, Vera significantly revises her account of the family's predeparture eating. What was originally presented in line 9 as in contrast to a substantial meal ("so they just had ehm crackers and biscuits") is represented as "they mucked into biscuits . . . they had quite a lot of biscuits and cheese" (lines 20/22). By the time Vera has completed her elaboration, Jenny is able to respond by registering her now-revised grasp of the situation (line 23). Here then, an utterance devoted to asserting a downgraded epistemic position solicits a response, and it does so in an "off the record" fashion. It both avoids directly evaluating Vera's family situation or her disappointments, and by soliciting the information in an "off the record" fashion, it also avoids drawing attention to the fact that an evaluation has been avoided (Heritage, 2011). ${ }^{3}$

A similar process is at work in the following case from the beginning of a meal. Mom is being served some food and requests only a small amount (line 1). At the same time, Virginia, her 14-year-old daughter, has been pressing her mother to pass on her plate to the server. Perhaps as a slightly irritated (and displaced) comment on Virginia's overly insistent behavior, Mom proceeds to contrast her own appetite with Virginia's (lines 4 and 6). Subsequently Virginia's brother Wesley initiates a sequence with a $\mathrm{K}-$ assertion (in this case, a type 2 knowable [Pomerantz, 1980]): "I thoughtju was dietin'." This assertion, made in the past tense and presented as a misapprehension, invites response from Virginia-the person in whose epistemic domain it undoubtedly falls.

\footnotetext{
${ }^{3}$ The use of questions to replace, and thereby elide, the production of actions due next was initially observed in Sacks's first lecture on conversation (Sacks, 1992a, pp. 3-11), and indeed there is a formal parallel between the sequence described by Sacks and the sequence described here. See also Heritage (2011).
} 
(9) [Virginia 1]

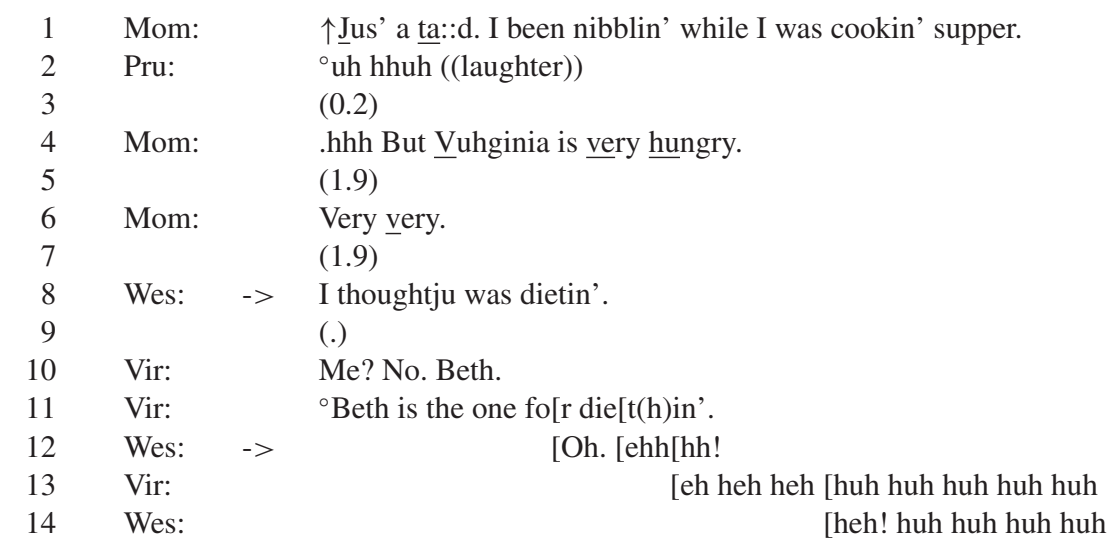

Virginia's initial three turn-constructional unit response is a marvel of economy. It initiates repair on Wesley's turn, rejects his assertion, and offers an alternative person as the "dieter" in the family-her sister Beth. Subsequently, she elaborates this turn with a full sentential assertion (line 11), that is acknowledged by Wesley with "oh" (line 12). By building his declarative Kassertion from Mom's slightly barbed comment, Wesley achieves stepwise topic transition, and "naturalizes" Mom's sanction of Virginia into a more neutral topic opening. ${ }^{4}$

Initiations through type 2 knowables and other forms of epistemic downgrade, though varied, are somewhat less direct and "on the record" than those launched through interrogative syntax. They also have the potential to be more seamlessly fitted to the contexts from which they emerge, permitting subtle stepwise topic shifts and sometimes, as in (8) and (9), elegant solutions to tricky interactional problems.

While this section has examined relatively overt $\mathrm{K}$ - claims in which matters in the recipient's epistemic domain are indexed using interrogative morphosyntax or other forms of epistemic downgrade, we can register that $\mathrm{K}$ - positions can be asserted with considerably more subtlety. In the following case, Lesley and her friend Carol have been reviewing which of their acquaintances are likely to be attending a community meeting. Carol asserts that "Joyce isn't going" and then observes that she didn't ring another friend Jillie (line 2).

(10) [Field C85-5: 28-370]

\begin{tabular}{|c|c|c|}
\hline Car: & & [So $\uparrow$ tha:t's that,].hh uh $\uparrow$ Joyce isn't going \\
\hline 2 & $->$ & $\begin{array}{l}\mathrm{I}-\mathrm{I}_{-}(0.3) \text { didn’t ring Ji:llie, } \\
(0.7)\end{array}$ \\
\hline Les: & $->$ & No I don't kno:w, \\
\hline
\end{tabular}

\footnotetext{
${ }^{4}$ As part of this process, $\mathrm{K}$ - initiations frequently, though tacitly, select next speakers (Lerner, 2003; Sacks, Schegloff, \& Jefferson, 1974). Lerner (2003, p. 190) notes that "when the requirements for responding to a sequence-initiating action limit eligible respondents to a single participant, then that participant has been tacitly selected as next speaker."
} 
5

6 Car:

7 Les:

8

9

10
(0.4)

${ }^{\circ}$ She would w-eh ${ }^{\circ}$ we[ $::$ : 11$]$ she-

[Well sh]e- jih- Joyce knows you're going so Jillie could ring you quite easily couldn't

$\operatorname{sh}[\mathrm{e}$.

[eeYes,

Evidently Lesley hears this as asserting a K- position about Jillie's plans because she responds to it as a request for information with "No I don't know." (line 4). Here a piece of information that is, a priori at least, in neither woman's epistemic domain is nonetheless made the object of an information request by a relatively indirect $\mathrm{K}-$ claim.

Moreover, as the following case shows, the assertion of a $\mathrm{K}$ - position can be completely wordless. In this pediatric visit, the child patient is asked about symptoms of vomiting and diarrhea. After a short silence (line 2), the child assumes a "thinking" face and articulates sounds compatible with hesitation (line 3).

(11) [San Gabriel: 206: 42-7]

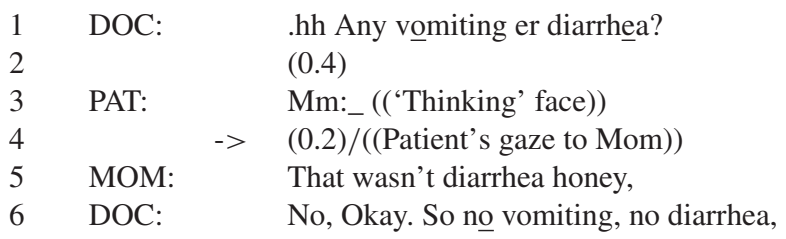

Subsequent to this, the patient turns to her mother, who treats the entire display as articulating a $\mathrm{K}$ - position and responds (line 5) with what the doctor takes to be an answer to her original question (line 6). ${ }^{5}$

In sum, just as speakers may deploy claims of $\mathrm{K}$ - epistemic status to initiate sequences, so too "change of state" proposals and assessments may invoke epistemic claims to close them. Across all the cases involving the use of "sequence-closing thirds" to terminate these epistemically driven sequences, the interaction progresses through a process of "boundaried" or "segmented" topic organization (Button \& Casey, 1985; Jefferson, 1984). Once sequences are launched, however, they can be expanded stepwise by turns that index a $\mathrm{K}$ - position in more subtle and indirect ways.

\section{K+ INITIATIONS}

The paradigm cases of speakers assuming a $\mathrm{K}+$ position are surely those in which they deploy pre-sequences to initiate a story or an announcement. In her account of preannouncement sequences, Terasaki (2004, p. 182) notes that they ordinarily contain (a) references to "news," (b) a preliminary evaluation of it as "good" or "bad," (c) some reference to its recency, and (d) an offer or a request to tell the news. Implicit in two of these characteristics-references to "news" and to its recency—are speakers' efforts to upgrade their K+ claims. In a return to (1), we can

\footnotetext{
${ }^{5}$ I owe this example, and its analysis, to Tanya Stivers.
} 
see that the recency is conveyed with " $t$ 'day" (line 2) and the status of the information as "news" is insisted upon with "I fergot t'tell y'."

(1) [Terasaki 2004]

1 Ron: I fergot t'tell y'the two best things that

2 happen'tuh me t'day.

3 Bea: $\quad$ Oh super.=What were they

4 Ron: I gotta B plus on my math test,

5 Bea: On yer final?

6 Ron: Un huh?

7 Bea: Oh that's wonderful

8 Ron: And I got athletic award.

9 Bea: REALLY?

10 Ron: Uh huh. From Sports Club.

11 Bea: Oh that's terrific Ronald.

Of course, access to the valence (Maynard, 2003) of the news may be sufficient for a "knowing recipient" to infer its content and lay claim to a "knowing" $(\mathrm{K}+)$ position. In the following sequence, a couple (A and B) has news for another couple (C and D), who are visiting. A's preannouncement makes reference to "good news," but while C gives a go-ahead for its telling (line 2), the other member of the visiting couple (D) claims to know it already (line 3). A and B both respond to D (lines 5 and 6) and abort the telling. Subsequently D indexes the news by referring to a "giant follicular lymphoblastoma" (lines 9-10) that, as it appears from line 11, was what A was planning to describe as the "good news."

(12) [KC4:1 (Terasaki 2004:189)]

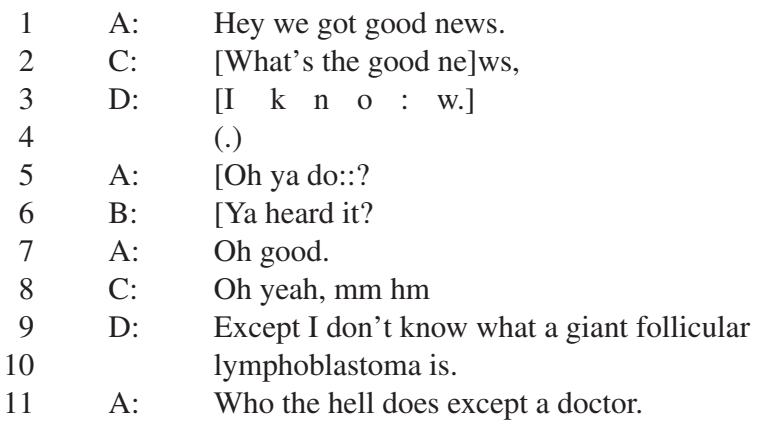

Here an indication of the valence of the news is sufficient to permit a recipient to announce a $\mathrm{K}+$ position, thereby undermining the $\mathrm{K}+$ epistemic status of the intending teller and, with it, the sequence.

In other cases, intending tellers give their recipients virtually no resources with which to assert a $\mathrm{K}+$ position:

(13) [Field C85:4: 34-42]

1 Les: $\quad$ hh Yi-m- You $\downarrow$ know I-I- I'm boiling about

2 something hhhheh[heh hhhh 


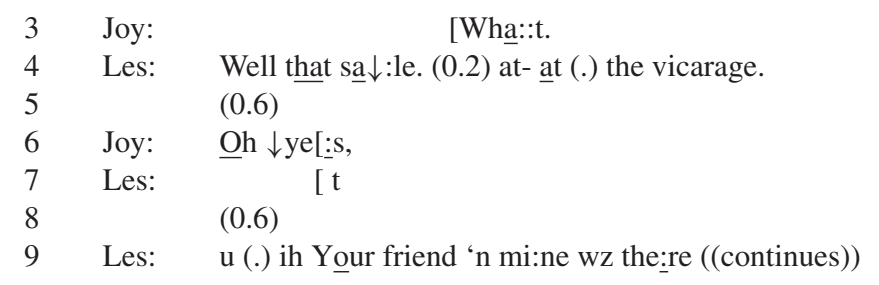

In this case, it is worth noting the exceptional opacity of Lesley's story preface "I'm boiling about something," which essentially provides no resources from which her recipient could infer the information and interdict the telling.

The risks of soliciting this kind of epistemic "blank check" are apparent in the following sequence, in which Shirley's opaque preannouncement ("That's not all that's new") gets a goahead (line 2), but the news announcement, once delivered, is rejected as news (line 8):

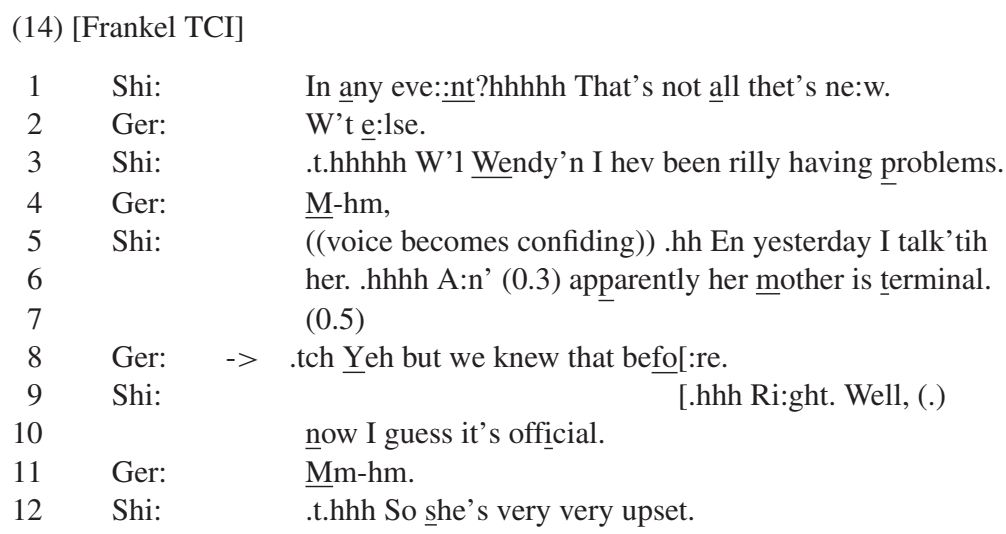

Under these circumstances, Shirley is forced to defend her announcement as news by invoking its "official" status (line 10). But the damage is done, and the risk of this kind of opaquely asserted, "blank check" $\mathrm{K}+$ position is apparent.

\section{INCREMENTAL K+ SEQUENTIAL MOVEMENT}

While Goodwin's (1979) analysis of the incremental construction of a turn to project a K+ position to a new, and somewhat knowledgeable, recipient is perhaps a paradigm case of small-scale incremental $\mathrm{K}+$ motivated movement, there are many cases of the use of slight $\mathrm{K}+$ adjustments to provide for the relevance of turns at talk. A return to (3) illustrates the point. Here, having responded to Lesley's questions about her garlic tablets, Mum volunteers the information that the tablets are compounded of "Garlic'n parsley" (line 6). While it is not entirely clear that this is intendedly presented as new information, Lesley certainly treats it as something to be evaluated as informative or not. Her response "confirms" Mum's turn rather than treating it as something to be 
registered as "new." Thus it is the epistemic status of this miniscule conversational contribution that is the object of Lesley's response here.

(3) [Field 1:1:89-94]

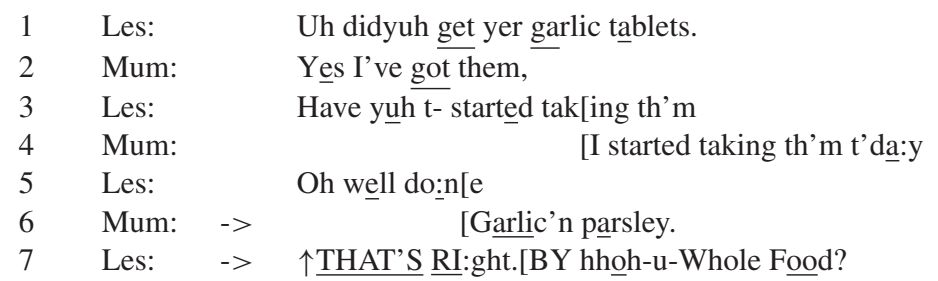

Similarly a further return to (1) shows a small addition to the sequence following Ronald's second news announcement:

(1) [Terasaki 2004]

$\begin{array}{rll}1 & \text { Ron: } & \text { I fergot t'tell y'the two best things that } \\ 2 & & \text { happen'tuh me t'day. } \\ 3 & \text { Bea: } & \text { Oh super.=What were they } \\ 4 & \text { Ron: } & \text { I gotta B plus on my math test, } \\ 5 & \text { Bea: } & \text { On yer final? } \\ 6 & \text { Ron: } & \text { Un huh? } \\ 7 & \text { Bea: } & \text { Oh that's wonderful } \\ 8 & \text { Ron: } & \text { And I got athletic award. } \\ 9 & \text { Bea: } & \text { REALLY? } \\ 10 & \text { Ron: } & \text { Uh huh. From Sports Club. } \\ 11 & \text { Bea: } & \text { Oh that's terrific Ronald. }\end{array}$

Following B's newsmark (Heritage, 1984; Jefferson, 1981b; Maynard, 2003) receipt of Ronald's announcement about his athletic award (line 9), Ronald adds information about the awarding organization. This in turn is folded into the overall sequence by B's [oh+ assessment] sequence-closing receipt at line 11 (see also the newsmark-extended sequence terminated at line 7).

Of course these small increments of information are as nothing compared to full-scale information-based "topical drift" of the kind found in (15). Here two teachers who have had recent experience of teaching the same class in the same school are discussing the class. Robbie's (repaired) opening statement about the children, with its reference to the need to "lick' $m$ into $\uparrow$ shape a $\downarrow$ gain," is equivocal between indexing discipline and instructional problems, and Lesley's response (lines $4-5,7$ ) picks the latter as its thematic core with its reference to "forcing" the writing and the math on to the children. This response is pitched as an agreement, offers substance to Robbie's comment about "licking them into shape," and invites agreement with the tag-question that simultaneously frames the substance of the term as epistemic common ground (Heritage, 2012/this issue; Heritage \& Raymond, 2005; Raymond, 2010; Stivers, 2010; Turner, 2008): 
(15) [Field May 1988:1:5:37-81]

1 Rob: $\uparrow A n$ ' I felt I'd achie::ved nothing'n the children're

2 really ah- (.) I feel (0.3) you know I need to lick'm

3 into $\uparrow$ shape a $\downarrow$ gain.

4 Les: .hhh Yes eh you haf to fo::rce the writing'n:: the maths

5 on them don't you. eh- (.) ih-eh[i:t's a ques]tion of $=$

6 Rob: [个个Y e : s .]

7 Les: =bulldozing it i-.hhhhh uh: into the curriculum at times

8 Rob: Yes do you- Did $\uparrow$ you: $\downarrow$ find that I mean is it just m:e.

9 I mean am I hhh I mean $\underline{I}$ consider myself pretty strict.

10 (.)

11 Les: Ye:s.

12 Rob: But I found them quite (0.2) you know I had t'keep

13 remind'n them t'be qui $\downarrow$ et. $=$

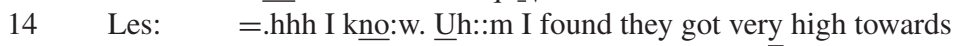

15 the end'v last te:rm..h[hhh

16 Rob: [Ye:[s

17 Les:

18 Les:

19 Rob:

20 Les:

Rob:

(0.6) .t.hhhhh (0.2) comic relief da:y?

[And I put it dow:n to uhm

Les: $\quad[$.hhh But now'v course you've got the concert $\downarrow$ looming

Ye:s?

A:n:d $\uparrow$ Eas $\downarrow$ ter.

$(0.3)$

$\mathrm{Ye}[: \mathrm{s}$ ? haven't[you.

Rob: [That's ri $\quad$ :ght.

...((10 line side sequence omitted $))$

Rob: Well it's quite a relief to hear you say that. $=\mathrm{c}[\mathrm{uz}$

Les:

[Yes I

found they got $\uparrow$ very high last term an' I kept saying to

Miss $\uparrow \uparrow$ Pelch:: that I hhhh e-were hers hi::gh? a:n:'she

wz saying no everything wz going along steadi $\uparrow$ ly'n.hh[hh

Rob:

I[(wonder) ]

[W'1

Les: $\quad[$ mine were] $\uparrow$ terribly ex $\uparrow$ cited. $\downarrow$ f'some[reason.

Rob: [Ye::h.

At line 8, Robbie renews her concerns, now unambiguously focused on classroom discipline with a "my side" telling, which prompts corroboration from Lesley (lines 14-15), and an account that explicates her children's behavior in terms of "Comic Relief Day" (a day in Britain devoted to charitable pranks) and the arrival of Easter (line 20), and which additionally offers a school concert as an account for Robbie's situation (line 22-23).

The introduction of a reference to "Miss Peltch" is a further occasion for both the soliciting, and offering, of information and opinion. Robbie's solicitation of Lesley's view of Miss Pelch 
is rewarded with a definite statement of opinion and the volunteered extension of this view to another teacher, "Freddie Masters."

(16) [Field May ‘88:1:5:82-93]

46 Rob: Well I wonder you know I don't always know what to

47 ma:ke of mih- Cynthia Pelch, what do yoü:. I don't

48 kno[:w.

49 Les: [.hh No, I think she- (.) $\uparrow$ a aa- well. b-di-Quite

50 honehhstly .hhh I think she c'n be ru:de. An', an' I

51 think Freddie Masters can too [:,

52 Rob: $\quad\left[\underline{\circ}\right.$ Oh:, I kno:w. ${ }^{\circ}$ I mean I

53 haven't run up against them but I do:n't find th'm

$54 \quad$ overhelpful. $=$

55 Les: $\quad=$.hhh No, (.) nuh- (.) no help at all fr'm Freddie

56 Masters an a:n' sometimes I've had f- almost to be:g.

$57 \quad . \mathrm{h}[\mathrm{hh}[$ for things.

Following Robbie's more guarded claim that she doesn't find them "overhelpful" (line 54), Lesley corroborates this view with a strongly escalated agreement ("no help at all") leaving her having "almost to be:g for things."

We have surely gone far enough with this sketch to see the ways in which epistemically relevant contributions drive this interaction forward in a kind of $\mathrm{K}+/ \mathrm{K}-$ seesaw, and the ways in which new contributions-as in the game of "Go"-permit topic drift in the classic stepwise progression first described by Sacks (1992b).

\section{EPISTEMIC ASPECTS OF TOPIC CLOSURE}

Just as the addition of new $\mathrm{K}+/ \mathrm{K}-$ contributions can drive topics forward, so topics will evidently atrophy in the absence of such contributions. In the following case Vera's son and family had arrived at her house for an overnight visit and, finding her away from home (at Jenny's house), were advised by a neighbor to go to there. At the beginning this sequence, Vera is congratulating herself on her foresight in telling the neighbor where to send them (line $1 / 3$ ), and Jenny counters with the observation that they might have worked it out on their own (lines 4-5). Vera agrees at line 6, whereupon there occurs a brief flurry of yes's (lines 7-9):

(17) [Rahman 14: 25-46]

$\begin{array}{llll}1 & \text { Ver: } & & \text { eeYe- Wasn' [it lucky? ah to:ld the w- told Missiz }= \\ 2 & \text { Jen: } & & {[\mathrm{Mm}-} \\ 3 & \text { Ver: } & & =\text { Richards tih te[11 }( \\ 4 & \text { Jen: } & & \text { [Ye::s thah wz smashing }<\text { mind he might } \\ 5 & & & \text { hev thoughtchu w'r up here anyw[ay } \\ 6 & \text { Ver: } & -> & \\ 7 & \text { Ver: } & -> & =\text { [Yes, }\end{array}$




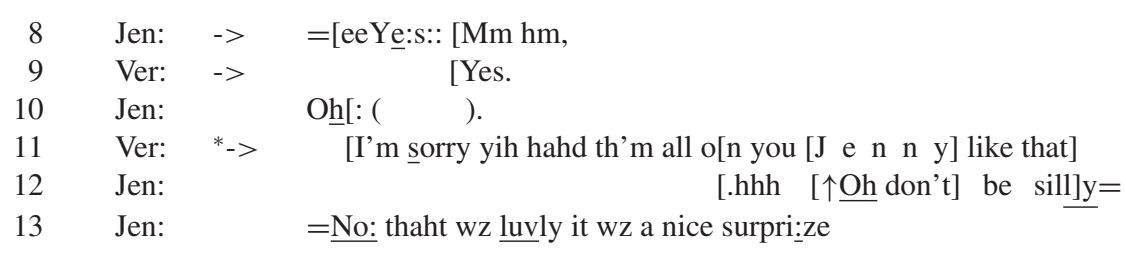

These yes's neither advance the sequence, nor wholly abandon it. In a large-scale analysis of topic in conversation, Jefferson (1981a) refers to this pattern as "topic attrition/topic hold." The topic is not abandoned, but no additional life is contributed to the topic through the seesaw of $\mathrm{K}-/ \mathrm{K}+$ epistemics, and as a result the topic withers. At lines 10 and 11 both women apparently start something new, and Vera wins out with an apology for the unexpected visitation of her family upon Jenny's household. ${ }^{6}$

Similarly, in (18) Michael, whose wife slipped a disc on Christmas morning (line 3), is faced with Edward's failure to grasp the significance of his added observation that she hadn't had the problem for 10 years (lines 8-9). After a second attempt (line 11) at getting Edward to register this point and failing (Heritage, 1998), Michael moves to the vacuously summative and closings relevant "Yes there we are" (line 13). This is echoed by Edward, who recompletes that turn with a further "Ye:s:," (line 17). Again the topic is neither advanced, nor (quite) abandoned:

(18) [Heritage 0II:2:4:2]

1 Edw: Well $\underline{\text { what }}$ a frightful thing $\underline{\text { How did }}$ it happen.

2 Mic: $\quad$ She just bent o:ver as we were getting ready to go out $h$

3 on Christmas [mo:rning.

4 Edw: [Oh:: my God.

$5 \quad(0.2)$

6 Mic: $\quad$.h Y(h)es i[t ha'n't

7 Edw: [uhh hu:hh, hu[:h ho:

8 Mic: [It hasn't happened for ten

9 yea:rs. $=$

10 Edw: $\quad=$ ukhh huukhh uhk $>$ Oh she's had it be fore. $<$

11 Mic: $\quad$ Oh yes but not for te(h)n y(h) ea(h) $[\mathrm{r}(\mathrm{h}) \mathrm{s}$.

12 Edw: [Oh::: Lo:rd.

13 Mic: -> Yes there we are.

14 Edw: $\rightarrow$ The:[re we are.

15 Mic: [.tch

$16 \quad$ (.)

17 Edw: -> Ye[:s:,

18 Mic: $\quad[$ and it's fl[attening)

19 Edw: * $*_{-} \quad$ [Well Michael anyway there it i:s, and ah:

20 an:d as I sa:y we uhm (.) we we: we would like to help if:

21 Edw: $\quad$ uh if she ever needs ah::.: she's (in need). You know?=

\footnotetext{
${ }^{6}$ Jenny's untranscribable start (line 10) is oh-prefaced, indicating something apparently "touched off" (Jefferson, 1978).
} 
In this context, Michael adds a tiny increment to his prior talk (line 18), but Edward, in an overlapping turn, moves to close the topic and the telephone call with an anyway-prefaced reuse of the same summative resource ("there it $\underline{\mathrm{i}} \mathrm{s}$, ,"). This becomes a bridge to a renewed assertion of the reason for the call (lines 20-21), which is of course a classic method of closing a call (Schegloff \& Sacks, 1973; see also Schegloff, 2005).

In the move toward topic closure in (18), both men deployed the somewhat formulaic expression "There we are," which adds no additional content to the talk and formulates no epistemic position. A similar role is played by idiomatic expressions that, as Drew and Holt $(1995,1998)$ have shown, play a significant role in topic closure and topic transition. A single representative example illustrates their argument. Here Lesley describes the recent demise of an elderly acquaintance, who died at 79, "still wo:rking.":

(19) [Drew and Holt 1998: 499]

Les: $\quad$ [Uh: uh-he wz the vicar's ward'n anyway he die:d suddenly this week .hhh and he w'z still wo:rking.

2

3

4

5

6 (0.3)

Mum: $\quad\left(\left[\begin{array}{ll}\text { ) } \\ \text { M }\end{array}\right.\right.$

Les: $\quad[$ He wz seventy ni:ne, (0.3)

Mum: $\quad$ My: wo:rd.

$(0 . \overline{2})$

Les: $\quad$ Y e $: s[$ he: $w z$ um

Mum: [(You've got s'm rea:l1) workers down the:re, heh

Les: $\quad$ He wz a p- uh: Ye:s. Indee:d hh He wz a (0.2) .p a buyer for the hoh- i-the only horse hair fact'ry left in England.

Mum: Good gracious,

Les: $\quad$ And he wz their buyer,

(.)

Mum: $\quad \mathrm{Hm}:::$

Les: $\quad$.t

Mum: $\quad \mathrm{Hm}$ :

Les: $\quad$-> So he had a good inni:ngs did[n't $\downarrow$ he.

Mum: -> [I should say so: Ye:s.

$(0.2)$

Mum: -> Marvellous.

$(0.2)$

Les: $\quad{ }^{*}->\quad$.tk.hhhh Anyway we had a very good evening o:n Saturda:

After some elaboration of his unusual employment as a horsehair buyer, which attracts relatively little response from Mum (lines 14, 18, and 20), Lesley concludes her account with an

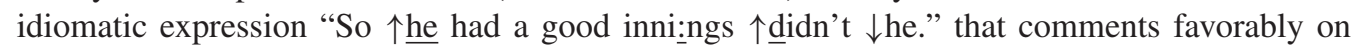
the length and quality of his life. ${ }^{7}$ Mum agrees with this without elaboration, whereupon Lesley shifts topic (lines 26-27). In their account of idiomatic expressions, Drew and Holt (1998) point

\footnotetext{
${ }^{7}$ The idiom is drawn from the game of cricket in which an individual batsman's innings can indeed be very long.
} 
to the way in which these expressions are part of a process of becoming "empirically disengaged." The parties, Drew and Holt observe (p. 503), "are not contributing further details but rather are assessing and summarizing the previously reported empirical information." Drew and Holt continue that

this disengagement from empirical details, managed through producing a figurative assessment, is highlighted by the way in which that assessment is not connected particularly or exclusively to its contiguously prior turn. Rather, the expression relates back over much of the prior talk/details, to assess aspects of the topic that have been talked about in earlier turns; indeed, the expression may refer back to and summarize or assess circumstances talked about over the whole of that topic. (ibid.)

In this context, it needs merely to be added that idiomatic expressions are, through their connection of a present circumstance to an unanchored abstraction, epistemically designed to add nothing new to the sequence and thereby to effectuate a move toward closing the topic.

In sum, new information, whether elicited from a $\mathrm{K}-$ position or volunteered from a $\mathrm{K}+$ position, is grist to the conversational mill, what Goffman (1964) once termed "conversational supply." While persons are evidently careful in the management of their epistemic domains relative to one another, speaking from one or the other position is part of an epistemic seesaw that can drive conversational sequence.

\section{DISCUSSION}

This article began with a paradox of sorts. On the one hand, there is a mass of evidence developed by linguists (especially in semantics and pragmatics) that attests to the relevance of the management of information flow both within the structure of sentences and in their evidential and other markings. On the other hand, there is the fact that the literature of conversation analysis, despite numbers of highly suggestive articles attesting to the transparent relevance of information flow in the organization of sequences, has not addressed its relevance as a feature of action and sequence organization. Yet once the relatively highly defined domain of adjacency pairs, together with their pre- and insert sequences, is departed from, there are few resources with which to understand the undoubted complexities of postexpansions and stepwise topic shift, which arguably make up the "dark matter," as it were, of conversational organization.

Evidence has been presented here that the "on the record" expression of $\mathrm{K}-$ and $\mathrm{K}+$ positions can be sequence initiating - the first movers of an epistemic seesaw motion that will tend to drive interactional sequences ${ }^{8}$ until a claim of equilibrium-for-all-practical-purposes is registered by the person who had previously assumed (or was assumed to be in) the $\mathrm{K}-$ position. It has also been argued that more subtle, off the record, or indirect expressions of $\mathrm{K}-$ and $\mathrm{K}+$ claims can be used to build or otherwise forward sequences that are already in play, often in stepwise topical progressions. Evidence was also reviewed that topic attrition and idiomatic expressions are ways of concluding sequences that specifically propose closure by adding no new informational supplies. Finally, in the case of "double-barreled" responses to intendedly informative utterances,

\footnotetext{
${ }^{8}$ Of course, sequences such as introductions and telephone openings, where requesting, or preferably offering, information about identity are fundamental (Pillet-Shore, 2011; Schegloff, 1986), are gateways to all the interaction that can follow and not simply local sequences.
} 
the turn components that respond to prior talk as informative (most commonly oh) are almost invariably the components of first resort, overwhelmingly occurring in turn-initial position. These observations suggest that conversational sequences, and not just sentences, are the objects of complex, intersubjectively validated, management of talk as information flow. In this process, interactants keep detailed score of "who knows what" and "who was told what" as a condition of the interpretation of utterances (Heritage, 2012/this issue), identity maintenance (Raymond $\&$ Heritage, 2006), and, if these arguments are correct, as a means of warranting conversational contributions and building expanded conversational sequences.

Just as these notions go beyond the adjacency pair as a resource for sequence construction, so too they may represent an underlying component of many adjacency pair firsts. In addition to their search for an actual commitment to some future course of action, canonical adjacency pair firsts such as requests for goods and services, invitations, offers, etc., also request information about the recipient's willingness to make the commitment, imparting a "double-barreled" dimension to their functioning that is not infrequently indexed in second pair-parts (Schegloff, 2007, p. 76), but less frequently in sequence-closing thirds.

\section{CONCLUSION: TALK'S WARRANTS}

Erving Goffman (1967, p. 45) once commented that "universal human nature is not a very human thing" and asked "What minimal model of the actor is needed if we are to wind him up, stick him in amongst his fellows, and have an orderly traffic of behavior emerge?" (p. 3). This article is not about a universal predilection among humans for giving and receiving information. Motivations for these latter must surely be as multifarious as human life itself. Instead, I am suggesting that giving and receiving information are normative warrants for talking, are monitored accordingly, and are kept track of minutely and publicly. It could, in principle, be different, but it is not. As noted earlier, the idea that "information" is a key element in communication, motivating and warranting contributions to talk, is not new. But this does not mean that it should be ignored. Conversation analysts, as I have suggested, have repeatedly addressed the conjoined issues of epistemics and "information" in conversation, clearly showing that speakers are sensitive to whether (and how) a turn will be informative for some particular recipient(s), and describing the organization of sequential resources for assuring the informative nature of a turn in advance, and for reassuring that same thing ex post facto. There is also, within CA, the beginning of a discussion of the massive sequential and evidential resources for the indexing of epistemic rights.

This article, then, has aimed at rearranging some of the elements of what we know already as a means to suggest the significance of epistemics in driving sequences of interaction. Underlying the conception of this article is a kind of "hydraulic" metaphor, according to which any turn that formulates a $\mathrm{K}+/ \mathrm{K}-$ imbalance between participants will warrant the production of talk that redresses the imbalance. Here the proposal is that asserting something from a $\mathrm{K}+$ position can be the basis for initiating or expanding a sequence, and that positioning oneself in a $\mathrm{K}$ - position can likewise motivate sequences or their expansion. In this context, I have tried to indicate the relatively unobtrusive and off-the-record ways in which $\mathrm{K}+$, and especially $\mathrm{K}-$, positions can be indexed as a means to this end and to suggest that sequence atrophy and closure can be a direct consequence when both parties abandon efforts to drive the $\mathrm{K}+/ \mathrm{K}-$ epistemic seesaw. 
Though there can be some subtlety to some of the sequential maneuvers described here, there is in truth nothing "occult" about what is being described. It is present in plain sight as an object of massive orientation by interactants at all times. However, for being continuously present in plain sight, the epistemic engine can easily become a "seen but unnoticed" feature of interaction (Garfinkel, 1967). In response to Schegloff's (2007) suggestion that there may be other principles of sequence organization other than that centered on the notion of adjacency pairs (p. 9), this article suggests that the exploitation of epistemic status and stance embodied in the notion of an epistemic engine may be one such principle. Much work will be required to explore its validity and, if viable, its ramifications.

\section{REFERENCES}

Button, G., \& Casey, N. (1985). Topic nomination and topic pursuit. Human Studies, 8, 3-55.

Chafe, W. L. (1994). Discourse, consciousness, and time: The flow and displacement of conscious experience in speaking and writing. Chicago, IL: University of Chicago Press.

Clark, H. H., \& Haviland, S. E. (1977). Comprehension and the given-new contract. In R. Freedle (Ed.), Discourse production and comprehension (pp. 1-40). Hillsdale, NJ: Erlbaum.

Drew, P., \& Holt, E. (1995). Idiomatic expressions and their role in the organization of topic transition in conversation. In M. Everaert, E.-J. Van der Linden, A. Schenk, \& R. Schreuder (Eds.), Idioms: Structural and psychological perspectives (pp. 117-132). Hillsdale, NJ: Erlbaum.

Drew, P., \& Holt, E. (1998). Figures of speech: Figurative expressions and the management of topic transition in conversation. Language in Society, 27, 495-522.

Garfinkel, H. (1967). Studies in ethnomethodology. Englewood Cliffs, NJ: Prentice-Hall.

Goffman, E. (1964). The neglected situation. American Anthropologist, 66(6), pt. II: 133-136.

Goffman, E. (1967). Interaction ritual: Essays in face to face behavior. Garden City, NY: Doubleday.

Goodwin, C. (1979). The interactive construction of a sentence in natural conversation. In G. Psathas (Ed.), Everyday language: Studies in ethnomethodology (pp. 97-121). New York, NY: Irvington Publishers.

Goodwin, C. (1986). Audience diversity, participation and interpretation. Text, 6(3), 283-316.

Grice, H. P. (1975). Logic and conversation. In P. Cole \& J. L. Morgan (Eds.), Syntax and semantics, Vol. 3: Speech acts (pp. 41-58). New York, NY: Academic Press.

Groenendijk, J. (1998). Questions in update semantics. In J. Hulstijn \& A. Nijholt (Eds.), Formal semantics and pragmatics of dialogue. Twente, The Netherlands: University of Twente Proceedings TWLT13.

Halliday, M. A. K., \& Hasan, R. (1976). Cohesion in English. London, England: Longman.

Hayano, K. (2011). Territories of knowledge in Japanese interaction. (Unpublished doctoral dissertation). Max Planck Institute for Psycholinguistics, Nijmegen, The Netherlands.

Heritage, J. (1984). A change-of-state token and aspects of its sequential placement. In J. M. Atkinson \& J. Heritage (Eds.), Structures of social action (pp. 299-345). Cambridge, England: Cambridge University Press.

Heritage, J. (1998). Oh-prefaced responses to inquiry. Language in Society, 27(3), 291-334.

Heritage, J. (2010). Questioning in medicine. In A. F. Freed \& S. Ehrlich (Eds.), "Why do you ask?”: The function of questions in institutional discourse (pp. 42-68). New York, NY: Oxford University Press.

Heritage, J. (2011). Territories of experience, territories of knowledge: Empathic moments in interaction. In T. Stivers, L. Mondada, \& J. Steensig (Eds.), The morality of knowledge in conversation (pp. 159-183). Cambridge, England: Cambridge University Press.

Heritage, J. (2012). Epistemics in action: Action formation and territories of knowledge. Research on Language and Social Interaction, 45(1), pp. 1-29.

Heritage, J., \& Raymond, G. (2005). The terms of agreement: Indexing epistemic authority and subordination in assessment sequences. Social Psychology Quarterly, 68(1), 15-38.

Heritage, J., \& Raymond, G. (in press). Navigating epistemic landscapes: Acquiescence, agency and resistance in responses to polar questions. In J.-P. De Ruiter (Ed.), Questions: Formal, functional and interactional perspectives. Cambridge, England: Cambridge University Press. 
Jefferson, G. (1978). Sequential aspects of storytelling in conversation. In J. Schenkein (Ed.), Studies in the organization of coversational interaction (pp. 219-248). New York, NY: Academic Press.

Jefferson, G. (1980). On 'trouble-premonitory' response to inquiry. Sociological Inquiry, 50, 153-185.

Jefferson, G. (1981a). Caveat speaker: A preliminary exploration of shift implicative recipiency in the articulation of topic. End of grant report to the Social Science Research Council [Great Britain].

Jefferson, G. (1981b). The abominable "Ne?": A working paper exploring the phenomenon of post-response pursuit of response. Occasional Paper No.6, Department of Sociology, University of Manchester, Manchester, England.

Jefferson, G. (1984). On stepwise transition from talk about a trouble to inappropriately next-positioned matters. In J. M. Atkinson \& J. Heritage (Eds.), Structures of social action (pp. 191-221). Cambridge, England: Cambridge University Press.

Kamio, A. (1997). Territory of information. Amsterdam, The Netherlands: John Benjamins.

Kamp, H. (1981). A theory of truth and semantic representation. In J. A. G. Groenendijk, T. M. V. Janssen, \& M. B. J. Stokhof (Eds.), Formal methods in the study of language; Mathematical Centre Tracts 135 (pp. 277-322). Amsterdam, The Netherlands: Mathematical Centre.

Labov, W., \& Fanshel, D. (1977). Therapeutic discourse: Psychotherapy as conversation. New York, NY: Academic Press.

Lerner, G. (2003). Selecting next speaker: The context-sensitive operation of a context-free organization. Language in Society, 32, 177-201.

Levinson, S. C. (2000). Presumptive meanings: The theory of generalized conversational implicature. Cambridge, MA: MIT Press.

Levinson, S. C. (2006). On the human "interactional engine". In N. J. Enfield \& S. C. Levinson (Eds.), Roots of human sociality: Cognition, culture, and interaction (pp. 39-69). London, England: Berg.

Levinson, S. C. (in press). Interrogative intimations: On a possible social economics of interrogatives. In J.-P. De Ruiter (Ed.), Questions: Formal, functional and interactional perspectives. Cambridge, England: Cambridge University Press.

Maynard, D. (2003). Bad news, good news: Conversational order in everyday talk and clinical settings. Chicago, IL: University of Chicago Press.

Pillet-Shore, D. (2011). Doing introductions: The work involved in meeting someone new. Communication Monographs, 78, 73-95.

Pomerantz, A. M. (1980). Telling my side: "Limited access" as a "fishing" device. Sociological Inquiry, 50, $186-198$.

Prince, E. F. (1981). Toward a taxonomy of given/new information. In P. Cole. (Ed.), Radical pragmatics (pp. 223-255). New York, NY: Academic Press.

Raymond, G. (2003). Grammar and social organization: Yes / No interrogatives and the structure of responding. American Sociological Review, 68, 939-967.

Raymond, G. (2010). Grammar and social relations: Alternative forms of yes/no-type initiating actions in health visitor interactions. In A. F. Freed \& S. Ehrlich (Eds.), “Why do you ask?”: The function of questions in institutional discourse (pp. 87-107). New York, NY: Oxford University Press.

Raymond, G., \& Heritage, J. (2006). The epistemics of social relations: Owning grandchildren. Language in Society, 35, 677-705.

Sacks, H. (1987). On the preferences for agreement and contiguity in sequences in conversation. In G. Button \& J. R. E. Lee (Eds.), Talk and social organization (pp. 54-69). Clevedon, England: Multilingual Matters.

Sacks, H. (1992a). Rules of conversational sequence. In H. Sacks (Ed.), Lectures on conversation (Vol. 1, pp. 3-11). Cambridge, MA: Blackwell.

Sacks, H. (1992b). Stepwise topical movement. In H. Sacks (Ed.), Lectures on conversation (Vol. 2, pp. 291-302). Cambridge, MA: Blackwell.

Sacks, H., Schegloff, E. A., \& Jefferson, G. (1974). A simplest systematics for the organization of turn-taking for conversation. Language, 50, 696-735.

Schegloff, E. A. (1972). Notes on a conversational practice: Formulating place. In D. Sudnow (Ed.), Studies in social interaction (pp. 75-119). New York, NY: Free Press.

Schegloff, E. A. (1986). The routine as achievement. Human Studies, 9, 111-151.

Schegloff, E. A. (2005). Word repeats as unit ends. Paper presented at National Communication Association Meetings, Boston, MA. 
Schegloff, E. A. (2007). Sequence organization in Interaction: A primer in conversation analysis (Vol. 1). Cambridge, England: Cambridge University Press.

Schegloff, E. A., \& Sacks, H. (1973). Opening up closings. Semiotica, 8, 289-327.

Shannon, C., \& Weaver, W. (1949). The mathematical theory of communication. Urbana, IL: The University of Illinois Press.

Sperber, D., \& Wilson, D. (1986). Relevance: Communication and cognition. Cambridge, MA: Harvard University Press. Stalnaker, R. (1978). Assertion. In P. Cole (Ed.), Pragmatics (pp. 315-332). New York, NY: Academic Press.

Stivers, T. (2010). An overview of the question-response system in American English. Journal of Pragmatics, 42, 2772-2781.

Stivers, T., Enfield, N. J., Brown, P., Englert, C., Hayashi, M., Heinemann, T., . . Levinson, S. C. (2009). Universals and cultural variation in turn-taking in conversation. Proceedings of the National Academy of Sciences, 106(26), 10587-10592.

Stivers, T., \& Hayashi, M. (2010). Transformative answers: One way to resist a question's constraints. Language in Society, 39, 1-25.

Stivers, T., \& Rossano, F. (2010). Mobilizing response. Research on Language and Social Interaction, 43, 3-31.

Terasaki, A. K. (1976). Pre-announcement sequences in conversation. Social Science Working Paper 99, School of Social Sciences, University of California at Irvine.

Terasaki, A. K. (2004). Pre-announcement sequences in conversation. In G. Lerner (Ed.), Conversation analysis: Studies from the first generation (pp. 171-223). Amsterdam, The Netherlands: John Benjamins.

Turner, P. (2008). Grammar, epistemics and descriptive adequacy: Question construction in out-of-hours calls to an on-call physician. Unpublished paper, Department of Applied Linguistics, University of California at Los Angeles.

Van Eijck, J., \& Visser, A. (2010). Dynamic semantics. In E. N. Zalta (Ed.), The Stanford encyclopedia of philosophy (Fall 2010 edition). Retrieved from http://plato.stanford.edu/archives/fall2010/entries/dynamic-semantics/ 